\title{
Parents' view on distance learning during lockdown. A national survey
}

\author{
Giulia Pastori, Valentina Pagani ${ }^{2}$, Andrea Mangiatordi, \\ Alessandro Pepe $e^{4,5}$
}

\begin{abstract}
During the COVID-19 emergency, between March and May 2020, Italy was in an almost complete lockdown situation and millions of Italian children of all ages, overnight, stopped going to school and started receiving telematic communications from teachers or educators. Lockdown and distance learning had a significant impact on the overall well-being of parents and students and this study represents a contribution to deepen the understanding of parents' perceptions and observations on it. The study was an exploratory cross-sectional quantitative research project and the data was gathered through a structured computer-assisted web survey, administered right after the total lockdown, between May 19th and June 2nd, reaching out to 6.905 parents of 9.802 primary and secondary school children (5-18 year old children). The data gathered offered a clear picture of the conditions in which distance learning occurred during the months of lockdown and reliably detected an overall stressful situation for many families and many children and adolescents. Results highlight the weaknesses of distance learning, lacking crucial functions that constitutively distinguishes an "in-person" school, of socio-cultural protection, parental support, and social arena.
\end{abstract}

Keywords: parents, distance learning, pandemic emergency, emotional and behavioral impact, quantitative methods.

${ }^{1} \mathrm{PhD}$ and Associate Professor at the Department of Human Sciences for Education "R. Massa" of the University of Milan-Bicocca.

${ }^{2} \mathrm{PhD}$ and Collaborator at the Department of Human Sciences for Education "R. Massa" of the University of Milan-Bicocca.

${ }^{3} \mathrm{PhD}$ and Researcher at the Department of Human Sciences for Education "R. Massa" of the University of Milan-Bicocca.

${ }^{4} \mathrm{PhD}$ and Researcher at the Department of Human Sciences for Education "R. Massa" of the University of Milan-Bicocca.

${ }^{5}$ Giulia Pastori is the scientific supervisor and coordinator of the study. She took care of the overall structure of the paper, and wrote Introduction, parr. 3, 8 (8.1, 8.2), and Conclusions. Valentina Pagani wrote parr. 1, 2, 4, 7 and collaborated in writing par 8.2, and par. 9. Andrea Mangiatordi wrote par. 5, 9 and collaborated in writing par. 7, and par. 8.1. Alessandro Pepe wrote par. 6and 10, and collaborated in writing par. 8 $(8.1,8.2)$. (From now on, unless otherwise specified, footnotes are edited by this paper's Authors, Editor's Note). 


\begin{abstract}
Durante l'emergenza da COVID-19, tra marzo e maggio 2020, l'Italia si è trovata in una situazione di lockdown pressoché totale e milioni di bambini italiani di tutte le età, dall'oggi al domani, hanno smesso di andare a scuola e hanno iniziato a ricevere comunicazioni telematiche da insegnanti o educatori. Il blocco delle attività didattiche in presenza e l'apprendimento a distanza hanno avuto un impatto significativo sul benessere generale di genitori e studenti: questo studio rappresenta un contributo ad approfondire la comprensione delle percezioni e osservazioni dei genitori su questa esperienza Lo studio è consistito in una ricerca quantitativa esplorativa trasversale; i dati sono stati raccolti attraverso un'indagine web strutturata, assistita da computer, somministrata subito dopo il lockdown, tra il 19 maggio e il 2 giugno scorsi, raggiungendo 6.905 genitori di 9.802 studenti di scuola primaria e secondaria, fra i 5 e i 18 anni di età. I dati raccolti hanno permesso di delineare un quadro piuttosto chiaro delle condizioni in cui ha avuto luogo la didattica a distanza durante i mesi del lockdown e hanno documentato in modo affidabile una situazione di stress generale per molte famiglie e molti bambini e adolescenti. I risultati mettono in luce i punti deboli della didattica a distanza, nella quale viene a mancare le funzioni essenziali che contraddistinguono la "scuola-in-presenza", di protezione socioculturale, di sostegno ai genitori e di arena sociale.
\end{abstract}

Parole chiave: genitori, Didattica a Distanza, emergenza pandemica, impatto emotivo e comportamentale, metodi quantitativi.

\title{
Introduction
}

The new decade has begun with the most unimaginable scenario. The COVID-19 pandemic outbreak has shattered life. In a matter of days, what is first and foremost a health crisis has also led to an educational crisis as country after country has ordered early childhood education and care (ECEC) services and school closures. The effectiveness of this measure in containing the disease and reducing the risk of infection in children and their relatives is still under debate (Brooks et al., 2020; Poletti, Raballo, 2020; Viner et al., 2020). Nonetheless, as of April 8, 2020, educational institutions were temporarily suspended in 188 countries while several other countries opted for localized closures (UNESCO, 2020; United Nations, 2020). Overall, such educational disruption, unparalleled in its global scale and speed, has altered the lives of more than 1.5 billion learners - over $91 \%$ of the total number of enrolled students in the world (Ibidem) -, their families, and their educators (Azevedo et al., 2020; Garbe et al., 2020; Viner et al., 2020).

To respond to this unexpected and unprecedented challenge, school systems in many countries around the world have attempted to rapidly transition to remote learning, playing a significant role in restoring - at least partially - the severed communication and relationships between 
educators, teachers, children, and families (Bhamani et al. 2020; Pagani, Falcone, Pastori, Zaninelli, 2020). As billions of children, adolescents and young people have become virtual-school learners, teachers have had to embrace new complexities and "reinvent" their professionalism to meet the challenge of distance teaching (Di Nunzio, 2020; Jones, Kessler, 2020; Kim, Asbury, 2020; Pagani, Passalacqua, 2020; SIRD, 2020).

During the COVID-19 emergency, between March and May 2020, Italy was in an almost complete lockdown situation and it was the first country in Europe to close all ECEC services (0-6 year old children), schools (5-19 year old children), and universities (19-25+ youth). As a unique event in our century for its characteristics and duration, distance learning was organized, in order to guarantee the continuation of relationships and didactic activities - suddenly interrupted and not reopened for a very long period (from March to September 2020). ECEC services, schools, teachers and parents were largely unprepared to manage it, in terms of infrastructures, PCs or other devices and training in the use of educational ICT (Information and Communication Technologies).

Millions of Italian children of all ages (Fontanesi et al., 2020), overnight, stopped going to school and started receiving telematic communications from teachers or educators, attending recorded and video lessons, receiving WhatsApp messages, tasks and activities to be carried out at home, using the technological devices available and for the lucky ones, with the support of one or two parents at home from the workplace, unemployed or teleworking. In addition to the impact on children's educational progress - likely particularly tough considering great educational inequality among socio-economic groups and regions in Italy (Angrist et al., 2017; Brunello, Checchi, 2005) - the lockdown and the distance learning had a significant impact on the overall well-being of parents and students. The sudden shift to remote learning caught families unprepared, putting more responsibilities on the shoulders of parents (and sometimes siblings or other family members) called on to «take on the new role of learning facilitators, pseudo teachers, and coaches» (Gabre et al., 2020, p. 45). Parents struggled to cope with work while having to take care of children and the house without any external support, not even grandparents, pillars of the Italian childcare system. Children were not only out of schools, but they also could not access any other activities or public places (such as parks, cinemas, or theatres).

This study wants to contribute to deepen the understanding of parents' experiences and perspectives during these months of school "at home”. A CAWI (Computer-Assisted Web Interview) survey, titled What 
do you think? Parents' view on Distance Learning, was conducted right after the total lockdown, between May 19th and June 2nd and reached out to 6.905 parents of 9.802 primary and secondary school children (518 year old children).

The analysis of the data collected in the study aims to respond to two key research questions:

- the first research question explores parents' viewpoints on distance learning (its characteristics and the conditions in which it took place at home, such as times, spaces, devices, teaching methodologies and instruments) and on their child/children's experience, in terms of participation, motivation and competences in dealing with it;

- the second one addressed the intra-house impacts of the lockdown and online schooling, focusing on the main emotions experienced by parents, their observations and perceptions of their children's emotions and behaviors.

\section{Online schooling: effects on parents' and children's well-being and bealth}

In general, parental involvement in student academic activities plays a significant role in their children's achievement in traditional school settings (Boonk et al., 2018; Epstein, 2018; Park, Holloway, 2017; Tan, Lyu, Peng, 2020). This becomes even more crucial in virtual learning environments due to the lack of the physical presence of teachers and the amount of time spent on learning at home (Bulkley, Fisler, 2003; Green, Hoover-Dempsey, 2007; Liu et al., 2010).

Research on online schooling - developed before the COVID-19 outbreak and greatly increased during the crisis - has shown that parents can foster students' responsibilities, motivation and perseverance during the learning process and grasp effective learning strategies (Liu et al., 2010). Nonetheless, distance education also asks parents to take on new and unfamiliar responsibilities, accompanied by an increasing feeling of pressure as well as uncertainty about the role they should play in their children's online learning (Boulton, 2008; Garbe et al., 2020; Liu et al., 2010; Murphy, Rodriguez-Manzanares, 2009). If remote learning makes some parents feel closer and more connected to their children, for others it mainly represents an additional burden (Selwyn et al., 2011) and an overwhelming struggle to balance employment demands, personal needs and the necessity to keep their children on schedule - especially if as- 
sisting multiple children with learning in the home (Garbe et al., 2020).

For these reasons, distance learning exacerbates existing socioeconomic inequalities and long-running vulnerabilities for fragile or marginalized families (Burgess, Sievertsen, 2020; Cardenas, Bustos, Chakraborty, 2020; Masonbrink, Hurley, 2020; STC, 2020a; Van Lancker, Parolin, 2020; Yip, 2020). Children from disadvantaged backgrounds are likely to struggle with remote learning more due to limited or nonexistent access to technological resources or the internet at home and less parental guidance (Burgess, Sievertsen, 2020; Masonbrink, Hurley, 2020; Murat, Bonacini, 2020; Oreopoulos et al. 2006).

\section{Studies on online schooling during the COVID-19 outbreak. National and international literature}

During the COVID-19 outbreak, the challenge normally posed by distance learning was worsened due to the experience of living through a global pandemic combined with social isolation and employment stress (for instance, due to salary reductions, at-risk jobs, or job loss). As highlighted by several studies rapidly conducted over this period, the cumulative impact of these factors had several detrimental effects on both parents' and children's health and well-being (Brooks et al. 2020; Brown et al. 2020; Cardenas, Bustos, Chakraborty, 2020; Günther-Bel et al., 2020; Masonbrink, Hurley, 2020; Morelli et al., 2020; Noble, Hurley, Macklin, 2020; Petretto, Masala, Masala, 2020; Segre et al. 2020; Spinelli et al., 2020; United Nations, 2020), like developing negative lifestyles regarding eating, the reduction of movement and physical activities, sleep disturbances and other psychological consequences (such as emotional disturbance, depression, anxiety, stress, irritability, etc.). Not surprisingly, research has documented that this exceptional "global homeschooling experiment" has fueled parents' worries not only about the impact of distance learning on students' academic achievement (Hoffman, Miller, 2020; Kuhfeld, Tarasawa, 2020; UNESCO, 2020) but also about the effects of school non-attendance on children's social development (Bhamani et al., 2020; Champeaux et al., 2020).

The impact of the school closures was particularly striking in Italy. On the one hand, schools in Italy were closed nationwide for more than six months (from March to September 2020) - an interruption, unparalleled in length compared to measures enacted in other countries. On the other hand, the effectiveness of remote learning unavoidably collided 
with the substantial lack of preparation on the part of schools, teachers and parents to face the abrupt switch to distance education (Mangiavacchi, Piccoli, Pieroni, 2020) in a country characterized by high educational inequality among socio-economic groups and regions, schools with underdeveloped IT infrastructures, teachers not trained in the use of ICT educational instruments, and with $12.3 \%$ of children aged 6-17 without access to a computer or tablet at home (reaching 20\% in southern Italy, Angrist et al., 2017; Brunello, Checchi, 2005; ISTAT, 2020; Mangiavacchi, Piccoli, Pieroni, 2020).

Until today, the studies that have explored the experiences of Italian families dealing with online schooling from the different perspectives of parents, students and teachers give us a picture in shades of grey. Parents and teachers agreed that during the COVID-19 lockdown in Spring 2020, there was a great mobilization of teachers and schools (Gigli, 2020; SIRD, 2020) and the majority of Italian children and adolescents had regular contact with their teachers and participated in online learning activities (Ardizzoni et al., Ciurnelli, Izzo, 2020; SIRD, 2020; Vuorikari, et al., 2020). Nonetheless, a small - yet not negligible - percentage of learners did not receive or participate in remote schooling activities as reported consistently by both families (Ciurnelli, Izzo, 2020; Vuorikari, et al., 2020) and teachers (Ardizzoni et al., 2020; SIRD, 2020): on average, between $1 \%$ in Vuorikari and colleagues' online surveys that reached over 1000 families with 10-18 year old children and $8 \%$ in SIRD's online survey that involved over 16000 teachers across all grades. Especially, children from disadvantaged families struggled with accessing distance learning and risked falling behind (Ardizzoni et al., 2020; Soriani, 2020; STC, 2020b).

Teachers recognized that families played a crucial role in learner access to distance education, supporting their children in using IC devices to interact with their peers and teachers and supervising their participation and the completion of the assignments given (Ardizzoni et al., 2020; Pagani et al., 2020; SIRD, 2020).

Parents appreciated teachers' efforts and willingness to overcome the new challenges imposed by remote schooling (Ciurnelli, Izzo, 2020; Gigli, 2020) and estimated that during the Spring lockdown, their children gained new digital competences (Vuorikari et al., 2020). They also valued distance learning as a way to restore the relationship between children and teachers (Ciurnelli, Izzo, 2020). However, they also reported a deep sense of frustration and fatigue connected with this experience (Ardizzoni et al., 2020), as they struggled to reconcile family and work life 
with the responsibility of assisting their children with distance learning - a task they hardly felt equipped for (Ibidem) and judged highly timeconsuming (Mantovani et al., 2020). Hence, parents often expressed an overall critical assessment of distance learning (Ardizzoni et al., 2020; Ciurnelli, Izzo, 2020).

During those months, parents also observed some signals of distress in their children, such as greater irritability and frequency of tantrums (in younger children), and anger (in older children), changes in compliance with rules, sleeping and eating disorders, increase of fears and mood changes (Mantovani et al., 2020). Of course, these changes could be related to the overall emergency experienced by children and adolescents. Nevertheless, it cannot be excluded that the difficulties in adapting to remote schooling, as reported by the few studies that directly consulted students (Ciurnelli, Izzo, 2020; STC, 2020b), could have played a part too.

The survey presented here, in continuity with other studies, wants to contribute to understanding the parental perspective on remote schooling experienced during Spring 2020 lockdown, focusing both on their own experience of it and that of their child/ren, to evaluate the intrahouse perceived emotional and behavioral impacts.

\section{The questionnaire: structure, topics, and dimensions}

We present original data collected by administering a questionnaire specifically designed for studying parents' perceptions, observations and the perceived emotional and behavioral impact of the lockdown and distance learning at the intra-house level, both on the parents themselves and on their children. The study was an exploratory, cross-sectional, quantitative research project and the data was gathered through a structured computer-assisted web survey (CAWS; Baker, 1998) compiled by a large sample of Italian parents. Data was collected using a Google Form sent to different groups and social media. Inclusion criteria were: 1) being a parent of children aged between 6 six and 18, attending school from primary to secondary second level; 2) being in Italy during lockdown; and 3) being exposed to distant learning practices. Exclusion criteria were not set.

The survey adopted closed-ended questions, Likert-type response scales (Wyatt, Meyers, 1987), and a differential semantic scale (Berlyne, Peckham, 1966; Osgood, 1964). For some questions, parents responded in reference to each child when there were more than one.

The questionnaire included six sections, as shown in Table 1. 
Table 1 - Main sections and topics

1. Family and home context

\section{School context}

3. Distance learning characteristics
Basic information on respondents' and partners' personal characteristics including: demographic background (i.e. gender, age, family characteristics, number of children, children' ages, location of residence, highest level of education, marital and parental status); labor market participation (employment, typology, hours per week, teleworking); characteristics of the home (web connection facilities, indoor space, outdoor facilities such as a balcony, a terrace, a courtyard; external help for childcare).

The characteristics of the schools attended by child/ren (public, private; specific pedagogical approach if any; characteristics of the families attending the school/s in terms of cultural and socio-economic backgrounds).

The conditions where the distance learning occurred regarding:

times (how many hours per week);

spaces and tools (equipment used by child/

ren such as pc, smartphone and tablet;

space available for all family members, web connection),

sync and async teaching methodology (sync video lessons and async recorded lessons; online journal to communicate tasks; messages through email and social apps; digital materials such as videos and books; shared digital spaces and documents, etc.);

level of child/dren's autonomy in dealing with distance learning, measured by the hours spent by parents to support child/ren.

Parents' general evaluation on distance learning and on its pros and cons in reference to child/ren's learning, interest, digital competence enhancement, social relationships, homework and free time, parental knowledge of school activities. 


\begin{tabular}{|c|c|}
\hline $\begin{array}{l}\text { 4. Child/ren's } \\
\text { participation and } \\
\text { relationships }\end{array}$ & $\begin{array}{l}\text { Parents' perceptions of child/ren's participation } \\
\text { (and the main reasons behind low participation) } \\
\text { and children's social relationships with teachers } \\
\text { and schoolmates before and during the lockdown } \\
\text { period, including their feeling of nostalgia for } \\
\text { teachers and schoolmates. }\end{array}$ \\
\hline $\begin{array}{l}\text { 5. Distance } \\
\text { learning efficacy } \\
\text { and satisfaction, } \\
\text { and emotional and } \\
\text { bebavioral (parents' } \\
\text { perception) }\end{array}$ & $\begin{array}{l}\text { Parental perception of the emotions felt towards } \\
\text { the distance learning of their child/ren. } \\
\text { Parental perception of their child/ren's emotional } \\
\text { and behavioral changes during the lockdown } \\
\text { period considering two sets of items: } \\
\text { internal emotional states; } \\
\text { emotional regulatory systems and behavioral } \\
\text { control. }\end{array}$ \\
\hline $\begin{array}{l}\text { 6. Worries and } \\
\text { priorities for the future }\end{array}$ & $\begin{array}{l}\text { Worries and priorities regarding the reopening of } \\
\text { schools in September (2020) and for the near future } \\
\text { of school, with a focus on the school-work-family } \\
\text { life balance in case of prolonged distance learning } \\
\text { (full or blended). }\end{array}$ \\
\hline
\end{tabular}

The analysis carried out for this paper focused mainly on sections 3 , 4 , and 5 .

\section{Ethics}

Data was stored anonymously, and participants were informed about the aims of the study. Participation in the study was voluntary and no monetary or financial rewards were offered. The study was carried out according to the ethical principles defined by the Declaration of Helsinki (World Medical Association, 2001) and the American Psychological Association Code of Conduct (American Psychological Association, 2010). Prior to recruitment, the study was approved by the ethics committee of University of Milan-Bicocca.

\section{Description of the sample}

As the participation in the survey was totally voluntary, it was not conducted using a sampling strategy, therefore we cannot claim to have representativity at the national level. Thanks to the relevant sample size 
and the ability to reach many Regions, some key variables used in the analysis are in line with national statistics reported by ISTAT (2018, 2019), but several others make the sample less accurate.

There were a total number of 6905 valid responses to the survey, with an average age of 42.2 (SD 5.47). A total number of 9802 children were accounted for, with an average age of 9.78 years (SD 3.04).

The majority of participants $(94.41 \%)$ were mothers, while only $5.14 \%$ were fathers. Grandparents constituted the smallest group $(0.09 \%)$ and other figures were $0.36 \%$. A partner was present in the same household for $89.04 \%$ of respondents.

It is accurate to say that the group of respondents was, generally speaking, relatively wealthy, with a higher concentration in the NorthWest of Italy (70\%) and a lower representation in the Center (20\%), and in the South $(10 \%)$ of Italy.

The education level of participants was a Secondary School diploma in $41 \%$ of the cases, while $38 \%$ had a University degree. Another $14.5 \%$ of the participants had post-secondary specialization courses or $\mathrm{PhDs}$. Partners had an average age of 44.71 (SD 5.78), with education levels that varied from secondary school diplomas $(47.57 \%)$, to University degrees $(28.84 \%)$, while fewer had a post-secondary diploma $(7.44 \%)$.

These figures were much higher than the $19.6 \%$ rate reported by ISTAT in 2019 for university degrees and post-secondary education altogether (2019).

The majority of respondents $(80 \%)$ were working women. Most of them $(67 \%)$ continued working during lockdown, often adopting a teleworking approach $(57 \%)$. Their occupations varied from office jobs $(62.22 \%)$ to autonomous and freelance jobs $(18.2 \%)$. There was a significant number of unemployed people $(15.67 \%)$ and people who were laid off $(3.72 \%)$. Only a small percentage $(0.19 \%)$ were retired.

Partners also, for the most part, were employees $(67.3 \%)$, with a higher degree of autonomous and freelance jobs (27.48\%) and fewer layoffs $(1.92 \%)$. Only $2.82 \%$ were unemployed at the time of participation, and retired people only accounted for $0.48 \%$ of participants. The average week for participants had 28 work hours, while they attributed an average 41 hours when responding about their partners.

Teleworking was a common condition: for $42.92 \%$ of respondents, there was at least one other adult in the house using a PC, a smartphone, and an internet connection during lockdown. It was less frequent $(2.73 \%)$ that there were two other adults online, with more than two only in the $0.87 \%$ of responses. 


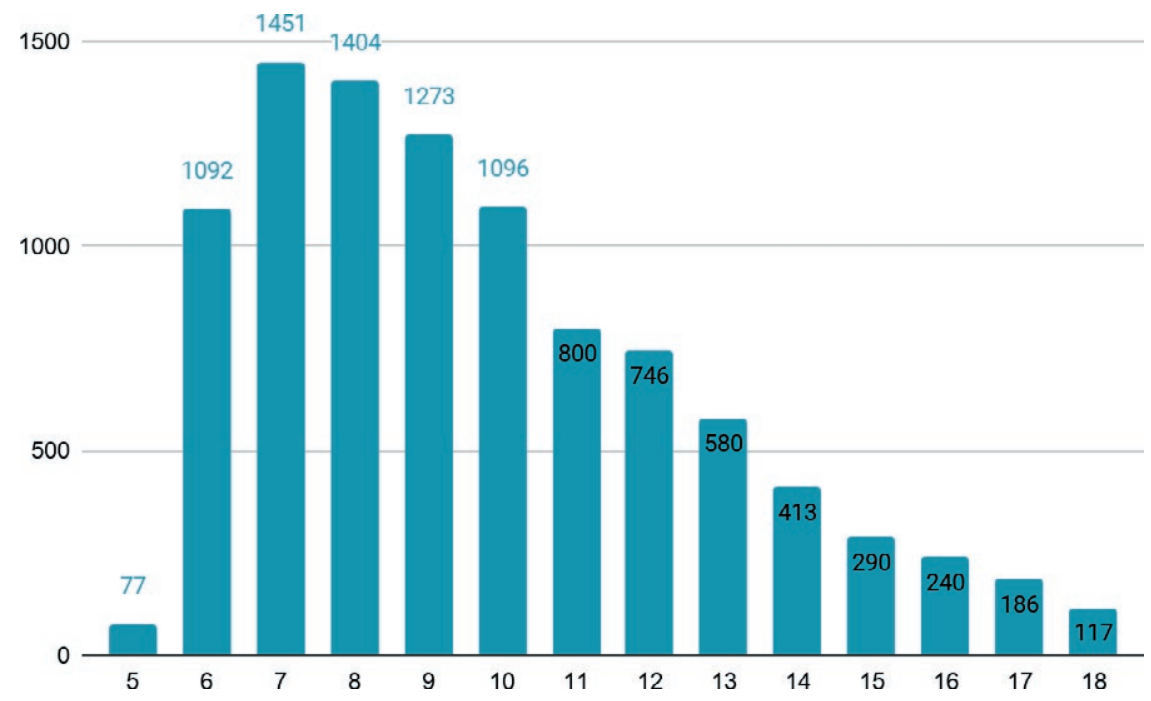

Fig. 1 - Children's distribution by age

The household did not include any other adult besides the respondent and her/his partner in $83.05 \%$ of cases, while $3.93 \%$ had one parent or parent-in-law living with them. A higher percentage $(6.56 \%)$ had two other adults in the household, with the remaining $6.44 \%$ of respondents stating that they had 3 or more other adults with them. Grandparents were present in $4.61 \%$ of the families. Some families $(3.86 \%)$ also had older children, working or studying at the university. In most cases $(2.85 \%$ of the overall total), there was just one child. In $3.6 \%$ of the cases, respondents had at least one elderly person living with them.

Not all families had equal access to private outdoor spaces: $24.36 \%$ of respondents had a terrace, $43.37 \%$ had a garden, and $24.11 \%$ a courtyard. A relevant number of participants, accounting for $18.38 \%$, declared no access to any outdoor space, while a very small number of families $(0,78 \%)$ had access to all three types.

There were 1.48 children per family attending primary or secondary school on average, against a national average of 1.34 (ISTAT 2018), which is higher in the North-West (1.39), the most represented area. 323 had a disability (3.4\%) and 10.7\% had a Learning Disability (like Dyslexia, Dyscalculia, etc.). The distribution of children by age is shown in Fig. 1, where it is possible to notice the high number of primary school children $(69 \%)$ followed by $20 \%$ of lower secondary school children and $11 \%$ of high school students. 
Responsibility for the child or children involved in the survey was shared with a partner in $52.24 \%$ of valid cases, while only $3.14 \%$ had the possibility to count on a paid babysitter and $12.4 \%$ had to resort to friends, neighbors, grandparents. There was a significant number of participants $(37.84 \%)$ who did not have any kind of help during lockdown.

\section{Data analysis}

Concerning the data analysis, data was analyzed using mono- and bivariate descriptive statistics, frequency analysis and correlational analysis. All bi-variate analyses were conducted by using age and school grade as explanatory variables, which resulted as the most significant variables in detecting some statistically significant differences. Two other variables were taken into consideration: namely, the presence of children with (learning) disabilities, and the availability of open-air spaces.

Given the size of the sample, one issue was about the $p$-value problem (i.e. the risk of detecting many statistically significant differences; Chatfield, 1995), meaning that results should be interpreted in terms of practical significance rather than be considered on the basis of their statistical significance. Consequently, $p$ was set to be less than .01 to compensate for the statistical effect of a very large sample size.

\section{The distance learning: how it took place, how it worked and its points} of strength and weakness

The data gathered offered a clear picture of the conditions in which distance learning occurred during the months of lockdown.

Despite the fact that most of the learners $(95.5 \%)$ benefited from remote schooling, mothers reported significant differences across school grades. Specifically, whereas primary school children were provided 7.5 hours of remote teaching per week on average, $47 \%$ received only 1 to 5 hours of online teaching activities per week and, worryingly, $4.1 \%$ did not receive online instruction at all. The situation was better at the secondary level, where all the students were provided with distance learning classes (on average 14.6 and 17.9 hours per week in lower and upper secondary school respectively). Nonetheless, $27 \%$ of lower secondary school students and $16 \%$ of upper secondary ones received less than 
10 hours per week of remote learning - around a third of the schooling hours expected for a typical school week.

Regardless of the school grade, the most common teaching pattern consisted in a combination of synchronous and asynchronous teaching and learning, albeit with relevant differences across school levels. Mothers of lower and upper secondary school students stated that the most frequent modalities for distance learning were synchronous online classes (respectively, $\mathrm{m}=5.8$ and 5.9, with scores ranging from $1=$ "not at all" to $7=$ "all the time"), followed by the use of shared spaces and documents $(\mathrm{m}=5.1$ and 5.2) and online journals to communicate tasks $(\mathrm{m}=5.1$ and 4.9). Conversely, among primary school children, communication with teachers via email or messenger apps (e.g. Whatsapp) was the highest reported $(m=4.4)$, followed by the use of online journals $(m=4.3)$ and synchronous lessons $(\mathrm{m}=4.2)$.

Students used a variety of digital devices to attend classes and carry out the required activities. The majority of mothers reported that their children $(60 \%)$ used computers exclusively. However, tablets and even mobile phones, despite providing a more constrained learning environment and limiting learners' possibility for interaction, were widely used across all school orders (these were the most frequently used devices in $22.9 \%$ and $13.6 \%$ of the sample, respectively).

According to our research participants, most children (ranging from $78 \%$ of upper secondary students to $88.3 \%$ of lower secondary students) took part in all the remote learning activities provided and completed all the assignments (the numbers varied from $70.9 \%$ in upper secondary school to $76 \%$ in primary school). Although with different priorities across school grades (see Table 2), the main reasons that deterred students from getting involved in distance education were demotivation, emotional distress in communicating at a distance and difficulty in participating without the support of an adult.

Not surprisingly, due to the high education level that characterized this sample, the emotional dimension and student's autonomous access to distance education largely defined the reasons for dropout during these months of remote schooling, whereas material and socio-economic factors mattered less.

Participants dedicated part of their time daily to helping out their children in school-related activities: the average number of hours spent this way by respondents was 2.98 , with a difference related to the age of the students. Fig. 2 shows the number of hours spent helping children according to their age, assuming an equal split for families where there 
was more than one school-aged child. As can be seen in Fig. 3, the curve was remarkably similar also when only families with one child were taken into account.

Table 2 - Descriptive statistics of obstacles in participating in remote schooling

\begin{tabular}{lccc}
\hline & Primary & $\begin{array}{c}\text { Lower } \\
\text { secondary }\end{array}$ & $\begin{array}{c}\text { Upper } \\
\text { secondary }\end{array}$ \\
\hline $\begin{array}{l}\text { [Difficulty in participating without the } \\
\text { support of an adult] }\end{array}$ & 4,95 & 4,42 & 1,93 \\
[Emotional distress] & 4,73 & 4,77 & 3,16 \\
[Demotivation] & 4,55 & 4,86 & 4,15 \\
[Lack of interest] & 3,58 & 4,09 & 3,37 \\
[Unclear requests for activities and & 3,10 & 3,93 & 2,92 \\
assignments from teachers] & & & \\
[Difficulty in hearing/seeing] & 3,03 & 3,42 & 2,50 \\
[Connection problems] & 2,92 & 4,00 & 2,86 \\
[Too much noise/confusion in the & 2,81 & 2,40 & 1,90 \\
house] & & & \\
[IC devices or internet not available] & 2,33 & 2,14 & 2,03 \\
\hline
\end{tabular}

Note: Sample size $(\mathrm{N})=6,905$; scores ranging from 1 (not at all) to 7 (very much)

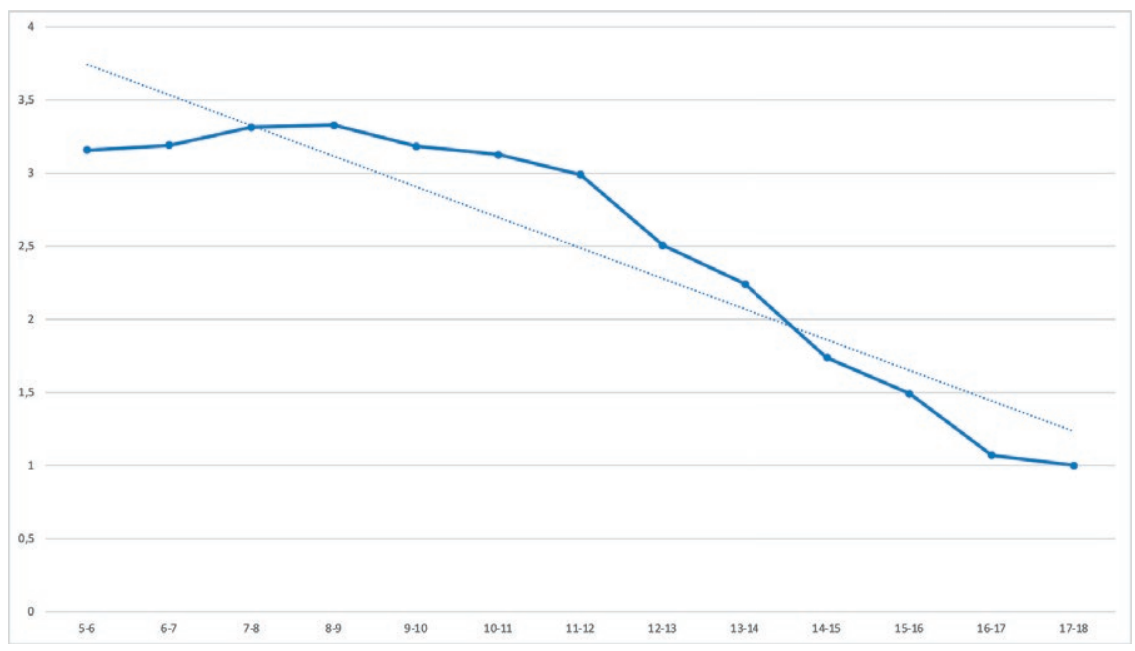

Fig. 2 - Average time in hours spent by parents helping children, assuming equal distribution among children of different ages $(\mathrm{N}=6905)$ 


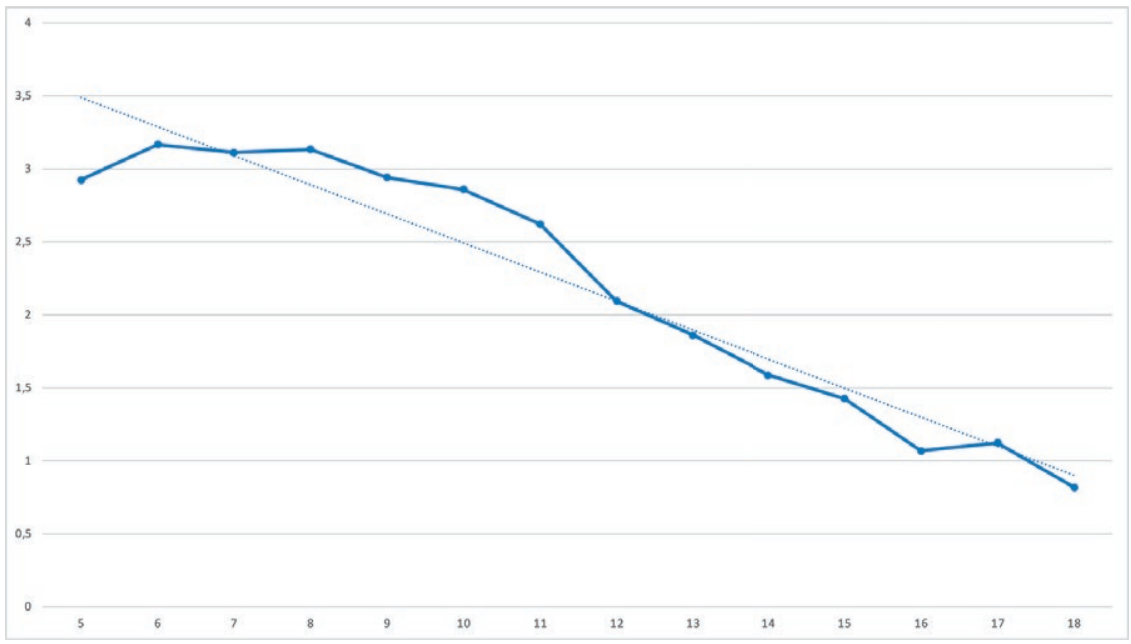

Fig. 3 - Average time spent by parents helping children, for families with only one child in school age $(\mathrm{N}=4008)$

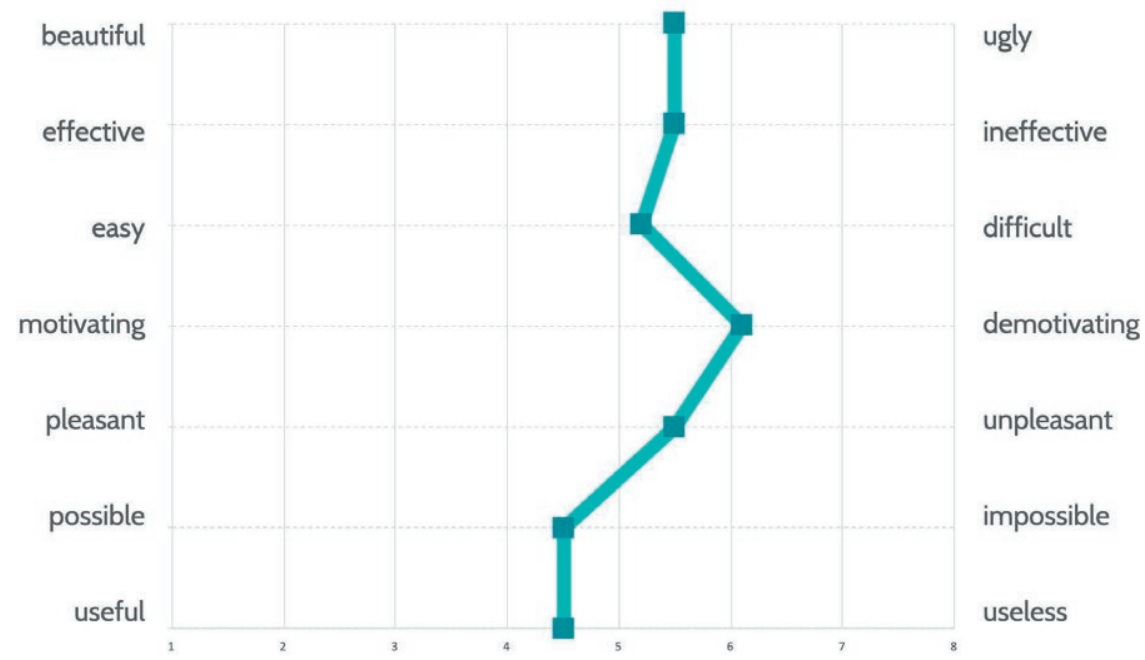

Fig. 4 - Differential semantic

Beyond asking about their overall satisfaction with their distance learning experience $(\mathrm{m}=2.71$, with scores ranging from $1=$ "extremely dissatisfied", to 8 = "extremely satisfied"), we proposed a differential semantic scale to obtain a more nuanced evaluation. The scale brought a critical assessment of remote schooling to light, described mostly as "demotivating", "ineffective", "unpleasant", "ugly" (see Fig. 4). 


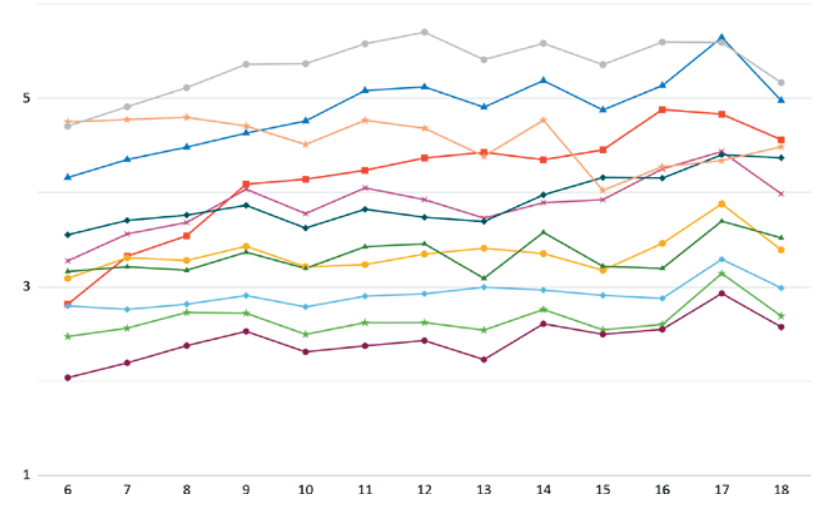

A Use of ICT for teaching/learning

- Autonomy

$x$ Interest in learning

- Balance between homework and free

time

- Flexibility of school hours

* Distance relationships with teachers

- Distance relationships with

schoolmates

- Parental knowledge of the school

activity

- Digital competence enhancement

$\triangle$ Variety in the didactic proposal

- Amount of homework

Fig. 5 - Distance learning pros and cons by children's age

Moreover, we detailed a question regarding the pros and cons of distance learning (see Fig. 5). We asked mothers to express (on a scale of 1 = "weakness", to $7=$ "strength", whereas the midpoint $4=$ "irrelevant" allowed respondents to express a neutral opinion) what they perceived as the strengths and weaknesses regarding the following elements: use of ICT for teaching/learning, child's autonomy, child's interest in learning, balance between homework and free time, flexibility of school hours, distance relationships with teachers, distance relationships with schoolmates, parental knowledge of school activities, child's digital competence enhancement, variety in the didactic proposal, amount of homework. Data showed that, regardless of the children's age, the difficulty to maintain relationships with schoolmates and teachers at a distance was the main reason behind the respondents' criticism, followed by their concern regarding the amount of homework assigned.

However, participants also recognized some strengths and positive implications of remote schooling. They pointed out that this experience contributed to enhancing children's digital competence and the use of ICT for teaching and learning. Noticeably, the perception of these benefits seemed to slightly increase with children's age, whereas mainly the mothers of younger children acknowledged greater parental knowledge of school activities as an opportunity offered by distance learning. Conversely, as children's age increased, child's autonomy lost its negative connotation. Considered a sore point by mothers of younger pupils (6-8 years old), it was regarded positively by parents of upper secondary school students. 


\section{Emotional and behavioral impacts on parents and children}

After considering distance learning characteristics and parental evaluation of them, the analysis of the data offered a picture of the emotional and behavioral dimension. The mothers interviewed were asked to express their perception and opinion regarding their personal emotions in reference to distance learning and their child/children's emotional and behavioral changes. Regarding parental emotions we mainly addressed internal emotional states (such as anxiety, anger, loneliness, serenity or satisfaction), regarding children, we proposed two sets of items, one set related to internal emotional states (for example, anger, boredom, anxiety, etc.) and another related to the emotional regulatory system and behavioral control (for example, autonomy in taking care of themselves, concentration in studying, reading and playing, etc.).

8.1. Parents' emotions: hard times, especially for primary school mothers

With regard to parental feelings about the prolonged experience with distance learning, Table 3 summarizes the mean scores of positive and

Table 3 - Descriptive statistics of parental emotional responses to distance learning

\begin{tabular}{lcccc}
\hline & Primary & $\begin{array}{c}\text { Lower } \\
\text { secondary }\end{array}$ & $\begin{array}{c}\text { Upper } \\
\text { secondary }\end{array}$ & p-value \\
\hline [Frustration] & 3.96 & 3.52 & 2.93 & $*$ \\
[Loneliness] & 3.35 & 3.32 & 2.98 & $*$ \\
[Anger] & 3.38 & 2.94 & 2.47 & $*$ \\
{$[$ Anxiety } & 2.83 & 2.66 & 2.34 & $*$ \\
{$[$ Inadequacy $]$} & 2.47 & 2.18 & 1.92 & $*$ \\
{$[$ Satisfaction $]$} & 1.46 & 1.63 & 1.72 & $*$ \\
[Indifference $]$ & 1.36 & 1.49 & 1.37 & \\
[Serenity & 1.02 & 1.22 & 1.36 & $*$ \\
[Sense of Freedom $]$ & 0.59 & 0.93 & 1.09 & $*$ \\
\hline
\end{tabular}

Note: ${ }^{*} \mathrm{p}<.001$; Sample size $(\mathrm{N})=6.905$; scores ranging from 0 (not at all) to 6 (all the time) 
5

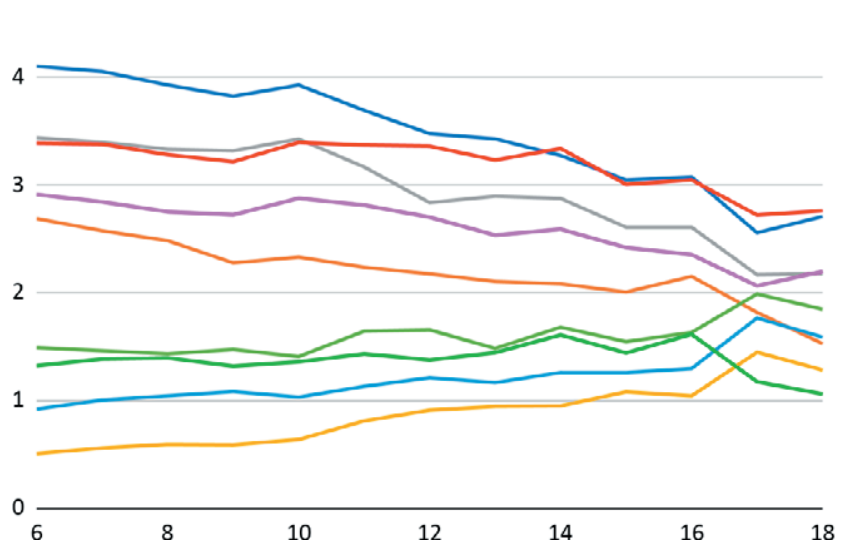

- [Frustration]

- [Inadequacy]

- [Anger $]$

- [Sense of freedom]

- [Serenity]

- [Satisfaction]

- [Loneliness]

- [Indifference ]

- [Anxiety]

Fig. 6 - Parents' emotions in relation to children's ages

negative parental emotions. The order follows a decreasing line of values, to make immediately visible how the predominant parental emotional scenario is negative, coherently with the results regarding their overall satisfaction with distance learning and its pros and cons.

Regardless of the school grade attended by children, the most cited emotions experienced by mothers were frustration $(\mathrm{m}=3.96)$, followed by anger $(m=3.38)$ and a feeling of loneliness $(m=3.35)$. Interestingly, the analysis of variance revealed that in all three cases, the mean scores decreased as a function of the school grade, with parents of children attending elementary school reporting higher scores regarding negative emotions. In a similar fashion, the set of positive emotions (sense of freedom, serenity, and satisfaction) reported very low general scores with statistically significant differences between the three groups. In fact, parents of older students attending upper secondary schools reported higher scores than parents of younger children.

It is important to underline that, however, in case of positive emotions, all average scores were in the lower bound of the possible range.

Fig. 6 above gives more detail regarding the variance of scores attributed to positive and negative emotions in relation to the children's ages (per year). We again see the general trend of a decreasing negative experience when the children's ages increase, and the two groups of lines, the lower one (under value 2) regarding positive emotions and the higher one regarding negative emotions, are constant across all children's ages. We can see a value gap in correspondence to twelve-year olds (between 


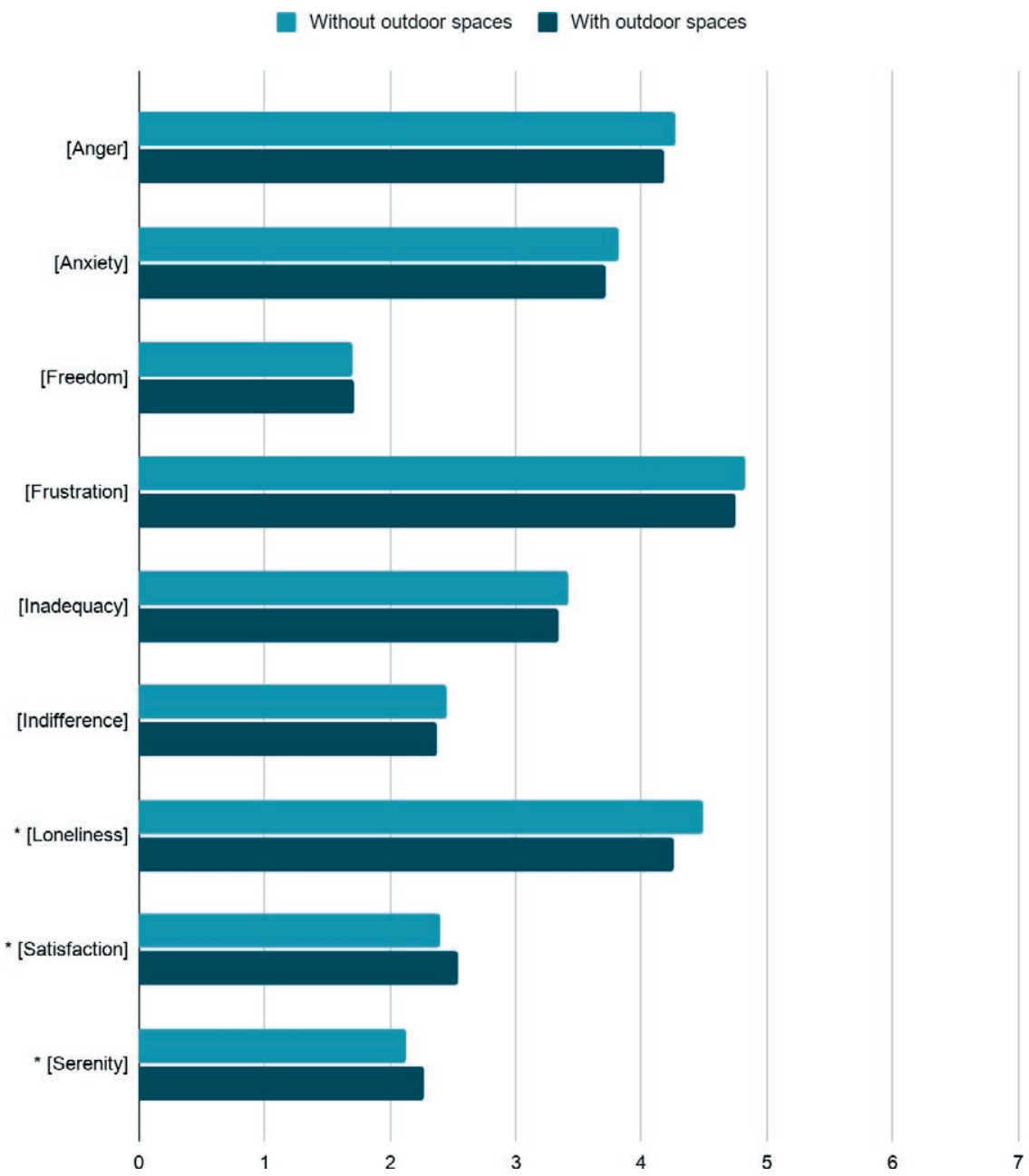

Fig. 7 - Mothers' emotions in households with or without access to outdoor spaces (Note: ${ }^{*} \mathrm{p}<.001$ )

the first and second year of the lower secondary school), especially if we focus on the two most conflictual emotions - frustration and anger.

To provide a more complex picture, we considered families who had access to outdoor areas compared to those living in houses with no outdoor space. Mothers in the former group defined themselves as more serene and satisfied, with a significantly lower degree of loneliness (see Fig. 7).

Furthermore, correlational analysis reveals moderate negative relationships between participants' perceptions of adequately balanc- 
ing homeschooling and work and the entire set of negative emotions (Frustration $\mathrm{R}=-.41$, Anger $\mathrm{R}=-.38$, Anxiety $\mathrm{R}=-.33$, Inadequacy $\mathrm{R}=-$ .29 , Loneliness $\mathrm{R}=-.29, \mathrm{p}<0.01)$. These results seem to suggest that the mother's fatigue during those months could not be attributed only to distance learning itself. Rather, it was probably associated with the difficulty in managing the upset balance between home and work. The high percentage of mothers who declared remote learning incompatible with work $(65.5 \%)$ and the significant number of women who considered the possibility of leaving their jobs if homeschooling continued during the following academic year $(30.3 \%)$ seem to support this interpretation.

\subsection{Mothers' views on children's emotional and behavioral changes: a stressful condition}

When parents reported their perceptions about children's behaviors and emotions expressed during the period of distance learning, the picture that emerged seemed to be mainly characterized by a set of negative emotions that predominantly affected younger children in primary schools, but also the other school grade children. As evidenced in Table 4 , the emotions with higher mean scores are all negative, not so much a

Table 4 - Children's psychological and behavioral changes: emotional internal states

\begin{tabular}{lcccc}
\hline & Primary & $\begin{array}{c}\text { Lower } \\
\text { secondary }\end{array}$ & $\begin{array}{c}\text { Upper } \\
\text { secondary }\end{array}$ & $\begin{array}{c}\text { p- } \\
\text { value }\end{array}$ \\
\hline [Expressions of boredom] & 4.82 & 4.82 & 4.54 & $*$ \\
[Mood swings] & 4.51 & 4.37 & 4.08 & $*$ \\
[Expressions of frustration] & 4.53 & 4.30 & 4.02 & $*$ \\
[Expressions of melancholy] & 4.08 & 3.99 & 3.89 & \\
[Anger] & 4.05 & 3.78 & 3.36 & $*$ \\
[Sense of loneliness] & 4.03 & 4.08 & 3.94 & $*$ \\
[Expressions of sadness] & 3.77 & 3.62 & 3.45 & $*$ \\
[Expressions of overall serenity] & 3.41 & 3.35 & 3.42 & \\
[Expressions of joy] & 2.4 & 2.72 & 3.08 & $*$ \\
\hline
\end{tabular}

Note: ${ }^{*} \mathrm{p}<.001$; Sample size $(\mathrm{N})=9,802$; scores ranging from 1 (not at all) to 7 (all the time) 
general feeling of sadness, but at the top is boredom, followed by mood swings and frustration, melancholy, anger, and loneliness.

In terms of the behavioral changes observed by mothers regarding their children connected to the emotional regulatory system and behavioral control, Table 5 shows that concentration (conceptualized as a

Table 5 - Children's psychological and behavioral changes: emotional regulatory system and behavioral control

\begin{tabular}{|c|c|c|c|c|}
\hline & Primary & $\begin{array}{c}\text { Lower } \\
\text { secondary }\end{array}$ & $\begin{array}{l}\text { Upper } \\
\text { secondary }\end{array}$ & $\begin{array}{c}\mathrm{p}- \\
\text { value }\end{array}$ \\
\hline $\begin{array}{l}\text { [Poor concentration (in studying, } \\
\text { reading, playing...)] }\end{array}$ & 4.94 & 4,57 & 4,22 & $*$ \\
\hline $\begin{array}{l}\text { [Lack of autonomy and need } \\
\text { for help (self-care, tasks, time } \\
\text { management)] }\end{array}$ & $4 ., 55$ & 4.00 & 3.24 & $*$ \\
\hline [Expressions of restlessness] & 3.98 & 3.92 & 3.64 & $*$ \\
\hline $\begin{array}{l}\text { [Increased communication (with } \\
\text { parents, siblings, other relatives, } \\
\text { friends...)] }\end{array}$ & 3.75 & 3.69 & 3.82 & \\
\hline [Anger outbreak] & 3.56 & 3.34 & 2.97 & $*$ \\
\hline $\begin{array}{l}\text { [Acquisition of new skills } \\
\text { (studying, dressing, washing, } \\
\text { cooking, cleaning...)] }\end{array}$ & 3.20 & 3.32 & 3.14 & \\
\hline [Hyperactivity] & 3.32 & 2.80 & 2.50 & $*$ \\
\hline [Tranquil mood and behavior] & 3.16 & 3.24 & 3.45 & $*$ \\
\hline $\begin{array}{l}\text { [Regressions of previously } \\
\text { acquired skills (studying, } \\
\text { dressing, washing)]. }\end{array}$ & 3.19 & 3.18 & 2.79 & $*$ \\
\hline $\begin{array}{l}\text { [Motivation (to play, to study, to } \\
\text { socialize)] }\end{array}$ & 2.94 & 2.82 & 2.89 & \\
\hline $\begin{array}{l}\text { [Increased autonomy (in self- } \\
\text { care, homework, leisure time } \\
\text { management)]. }\end{array}$ & 2.76 & 3.34 & 3.34 & $*$ \\
\hline $\begin{array}{l}\text { [Increased concentration (in } \\
\text { studying, reading, playing...)] }\end{array}$ & 1.94 & 2.20 & 2.35 & $*$ \\
\hline
\end{tabular}

Note: $* \mathrm{p}<.001$; Sample size $(\mathrm{N})=9,802$; scores ranging from 1 (not at all) to 7 (all the time) 
complex competence that includes not only study tasks, but also reading for pleasure or playing) and autonomy in self-care in doing tasks or in managing time are the two main behavioral domains that raised concern. In the hierarchy of values attributed by the opposite items "poor/increased concentration" and "lack of/increased autonomy", the extreme poles, unequivocally indicated a negative trend.

The hypothesis of greater tranquility or the acquisition of skills that regarded not only studying but also dressing, washing, cooking, cleaning, do not seem to demonstrate a particular positive trend, while indicating nonetheless an increase in communication with parents, siblings, or other people.

Overall, parents' perceptions suggest that their children's condition was stressful. In fact, poor concentration $(\mathrm{m}=4.94)$, mood swings $(\mathrm{m}=4.51)$, frustration $(\mathrm{m}=4.53)$, boredom $(\mathrm{m}=4.82)$ and a lack of autonomy $(\mathrm{m}=4.55)$ describe a set of symptoms often seen in literature to be indicators of psychological distress or consequences of challenging situations in children (Centifanti, Williams, 2017; Nader, 2007; Veronese, Pepe, 2017; Veronese et al., 2018). Importantly, variance analysis revealed that almost all negative emotions' scores were lower in higher secondary school students with respect to primary and lower secondary school children.

This condition can be detected across all of the children's ages, as can be seen in the two figures below (Fig. 8 and Fig. 9), though values that indicate a slightly more positive picture for children from age 13 on.

With respect to families who had access to outdoor spaces, there were significant differences in the majority of the variables connected to changes observed in children's emotions and behaviors: feelings of joy and serenity were less rare, but in general feelings like boredom and sadness, as well as loneliness, were perceived as stronger by those who could not count on the availability of external spaces.

Something similar happened in the observed psychological and behavioral changes, where there was a significantly stronger perception of higher levels of restlessness, hyperactivity, and regressions regarding skills for those who have no outdoor spaces available. On the other hand, parents observed lower levels in the acquisition of new skills, tranquility, and motivation in studying, reading, and socializing (Fig. 10).

Generally, being part of the group who have gardens, courtyards and terraces most likely indicates a higher socio-economic status. These families tend to experience fewer problems regarding connectivity, communication with teachers and noise in the household. The elements of 


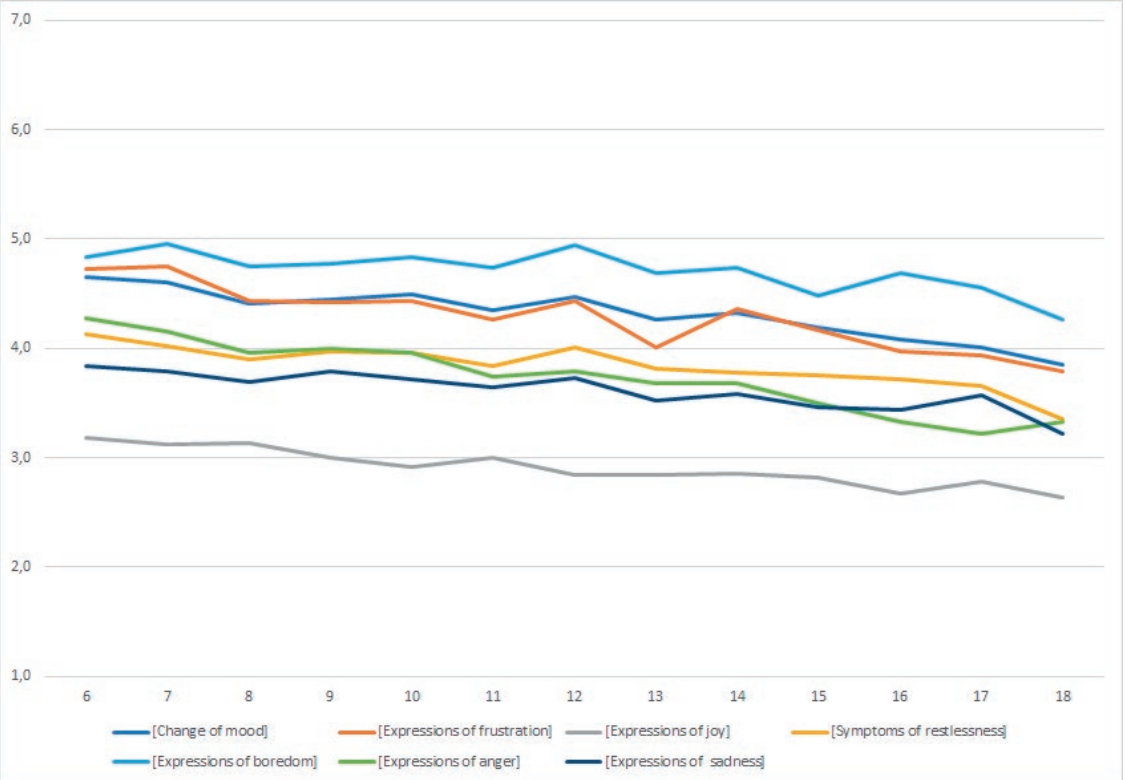

Fig. 8 - Children's emotional internal states per age

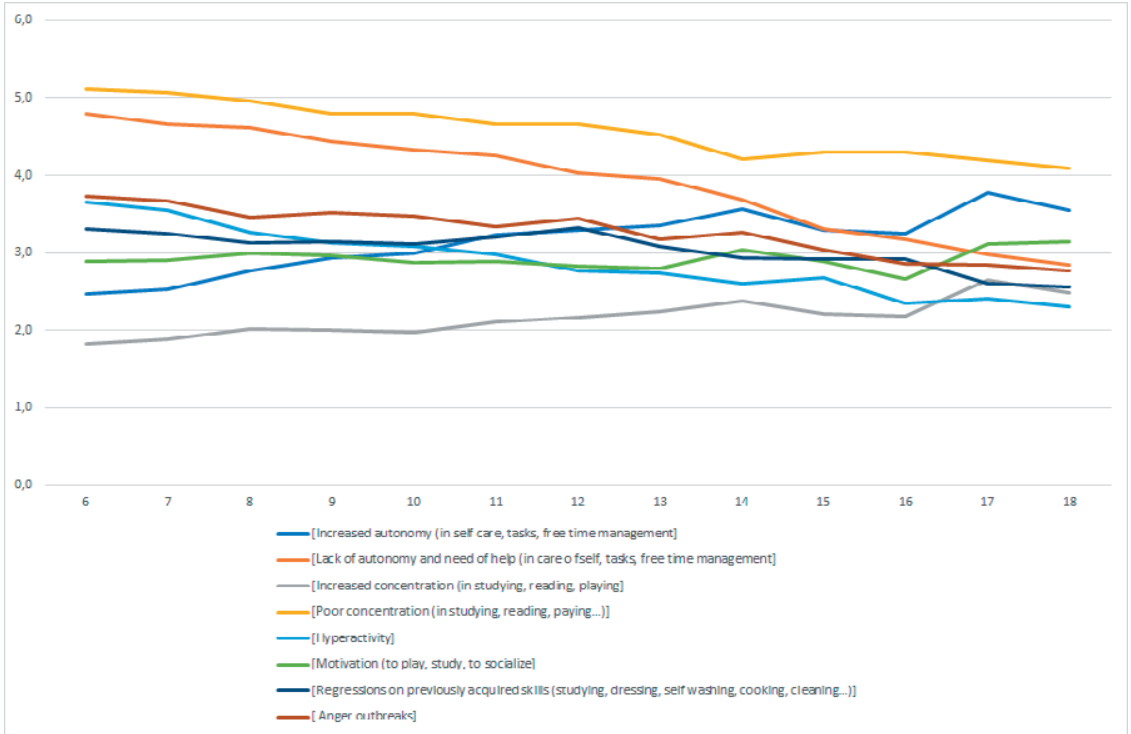

Fig. 9 - Children's behavioral changes per age 


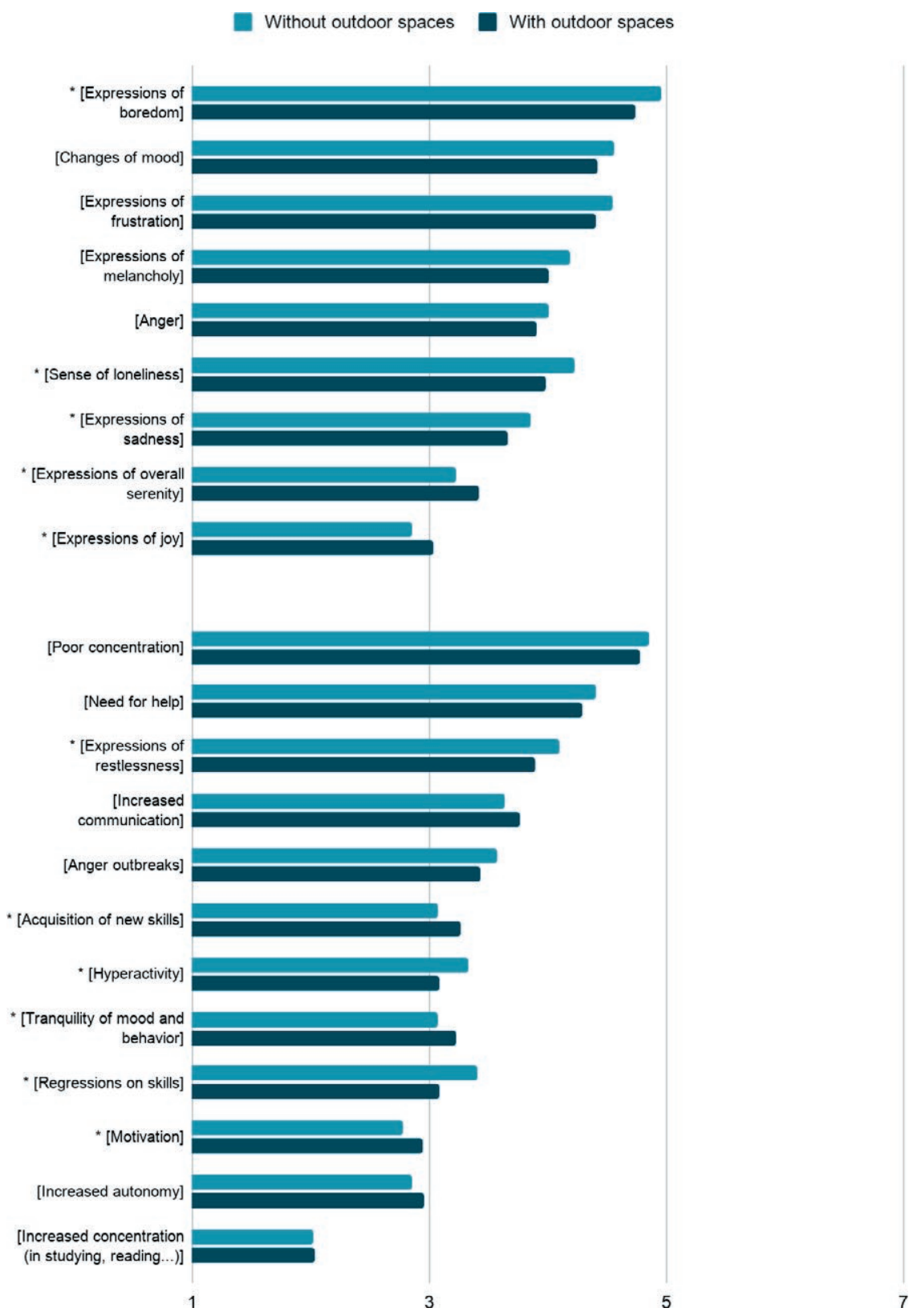

Fig. 10 - Children's emotions and behavioral changes with and without outdoor spaces (Note: $* \mathrm{p}<.001$ ) 
remote teaching that were more appreciated by parents living in this specific group were flexibility, balance between class activities and homework, the amount of assigned homework and the relationship with technology.

\section{Children with Special Educational Needs}

Families with children with disabilities experienced more difficulties compared to other families in the sample. The 289 families in this condition were closely compared to 700 other families, extracted randomly from the overall group of respondents. This comparison group was similar to the target in terms of age of the respondent, education level and location.

The exact same procedure was followed for families with at least one child with a Learning Disability (LD, such as Dyslexia, Dyscalculia, Dysorthographia, and Dysgraphia).

The two groups were kept separate to reflect Italian laws about special education: students with disabilities receive a different kind of specialized assistance from Inclusive Education teachers. There were 924 families with at least one child with LD, for a total number of 1049 children (1.14 per family), and they were compared to a random sample of 1500 other respondents.

One initial remark can be made about the support received by children with disabilities: among their parents, only $16.37 \%$ confirmed that their children got all the support assigned to them, while $38.07 \%$ received limited support and $45.55 \%$ did not receive any support at all.

Looking at what parents said about the pros and cons introduced by remote teaching, their children's autonomy was more of an issue for families with at least one child with a disability $(\mathrm{p}<0.001)$. The same was true for children with LD, where differences were also visible in terms of the children's interest in the distance learning $(\mathrm{p}<0.001)$ and in the perception of the parents' ability to cope with the requirements of their work and family life as well as the requests from their children's schools $(\mathrm{p}<0.01)$. The perception of knowledge of what kind of activities were proposed at school was higher for parents of children with LD $(\mathrm{p}<0.01)$.

In terms of hours spent helping children, both the families of children with disabilities and children with LDs had highly significant differences compared to the related samples ( $p<0.001$ in both cases). The 


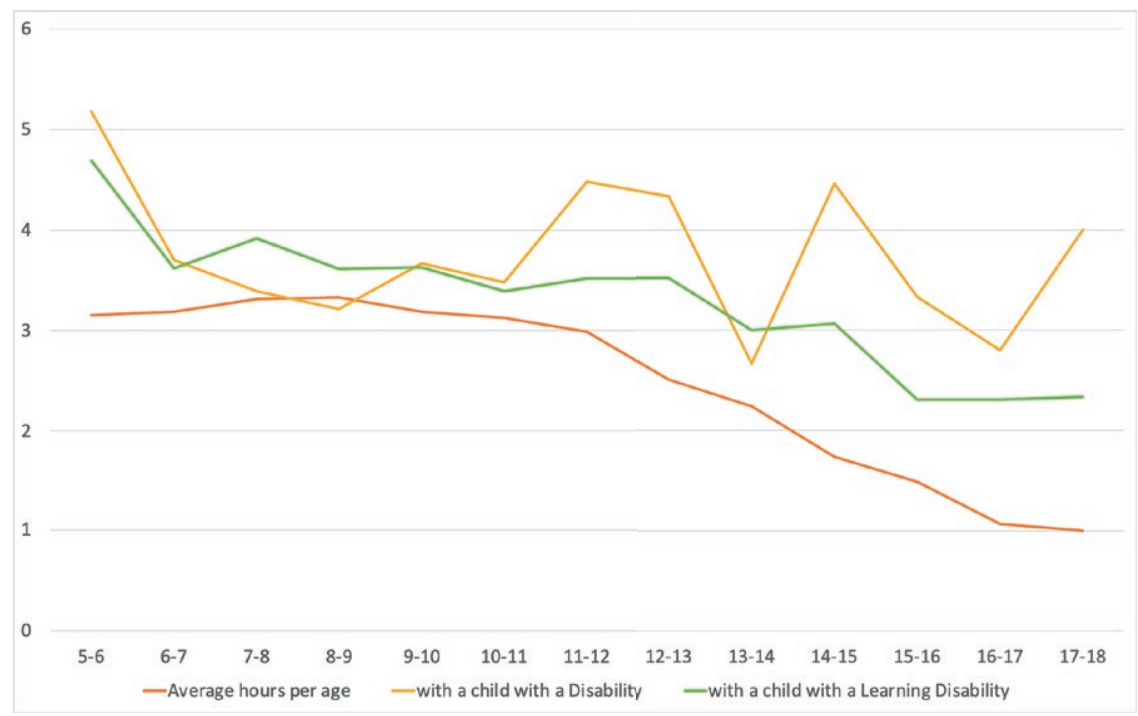

Fig. 11 - Daily support hours in families with children with disabilities and with children with LDs, per age of the oldest child

figure (Fig. 11) shows the average amount of support hours stated by parents, comparing the overall survey and the two subgroups of families with children with disabilities and LDs.

The feelings reported by parents of children with disabilities had higher degrees of a sense of inadequacy $(\mathrm{p}<0.01)$, which was more significant in parents of children with LD, coupled with a higher degree of anxiety $(\mathrm{p}<0.001)$.

Moreover, parents of children with disabilities and those with children with LDs noticed multiple behavioral changes in them, like increased restlessness and hyperactivity (more than in other families), paired with higher degrees of regressions towards states of dependence from the adults in the house, leading to lower perception of autonomy. Anger outbursts were described as more frequent, as well as mood changes, leading to darker feelings for children with disabilities. This also had, in the parents' view, a negative impact on academic and communication skills.

In terms of teaching and learning activities, we noticed that the group of parents with at least one child with a disability saw issues in the emotional domain become the cause for not participating in the activities or for not doing homework. If the lack of clarity was sometimes a barrier 
for participating in the remote teaching activities, some major, significant differences were reported in the ability to hear and see, as well as in the need for support from an adult. Such measures were less reliable than those referred to the respondent, hence they are presented simply to complete the picture of the parents' view on the lockdown and distance learning experience.

\section{Limits of the study}

As in the case of other studies, the present work presented some limitations that should be addressed. First, the data collection was based on self-reported quantitative measures administered via Computer Assisted Web Interview (CAWI). This means that vulnerable families (i.e., perhaps the subjects more affected by the pandemic emergency) were likely to be underestimated in the sample's composition. Besides, the use of self-reported quantitative scores affected the results in terms of common variance method (CMV; explained variance attributable to measurement methods rather than to the construct themselves; Pallavicini, Pepe, 2020; Podsakoff, MacKenzie, Lee, Podsakoff, 2003). In addition, other sources of quantitative bias (e.g., response style or the effects of other confounding variables; Veronese, Pepe, Alzaanin, Shoman, 2020) are likely to have been present. Then, self-report measures are inherently less accurate than clinical interviews when it comes to assessing detrimental psychological effects of environmental conditions distress (Boals, Hathaway, 2010), mostly when parents observed children reactions (Brazzelli, Grazzani, Pepe, 2021; Ornaghi, Pepe, Agliati, Grazzani, 2019).

Second, the research design was exploratory and cross-sectional, meaning that the results should not be interpreted in terms of causality (Bollen, Pearl, 2013) but, on the contrary, we agree with Pearl's (2012) position that causal relations in observational studies «can only be substantiated from a combination of data and untested theoretical assumptions, not from the data alone» (ivi, p. 2).

In addition, data were gathered during a period of global pandemic health crises and local national strict lockdown. In cases such as this, three different potential sources of psychological distress can be identified: the fear of the COVID-19, the combined effects of limitation of personal freedom and the contraction of general levels of social support, and the sudden shift from traditional learning to distance learning. 
From this point of view, it was essential to read the present study results with caution only hypothesizing the effects of one of those dimensions on socio-emotional distress. However, by using a large sample, this study's results can offer important indications and reflections to both policymakers and stakeholders on the management of transition in a time of emergency.

\section{Conclusions}

This study, in line with other Italian and international studies relating to the pandemic emergency period of the Spring 2020 reported in the introductory paragraphs, reliably detected an overall stressful situation for many families, but also for many children and adolescents as seen through the eyes of their parents.

We will summarize some particularly important results in order to formulate some conclusive reflections.

First, we observe that the study was configured as a "spontaneous" gender study, because almost all of the respondents were mothers, even though the questionnaire was potentially addressed to both parents, or other guardians of minors attending school. It seems plausible to us to interpret this characteristic of the sample as a first important result that indicates how the restrictive measures of the lockdown and the absence of in-person school support had greater repercussions on the lives of women-mothers than on fathers.

The sample was composed mainly of families with a medium-high education level. Therefore, we can assume that they had good cultural resources to face the challenges posed by the pandemic situation, an understanding of the general situation and the requests posed by distance learning, as well as good instrumental resources, even though $22 \%$ of children used mobile phones for distance learning.

Even within these "favorable" conditions, the prevailing perception of mothers that emerged from the data collected was that of fatigue and stress, attributable both to the overall pandemic situation, the restrictive conditions of life during lockdown and distance learning. This, on the one hand, occupied children's time and guaranteed a minimum level of didactic and social continuity, towards which gratitude emerged in this study and others (Ciurnelli, Izzo, 2020; Gigli, 2020); on the other hand, it also represented an additional burden on the shoulders of women, especially those with children who were of primary school age and in first 
and second year of lower secondary school, workers, and possibly with children with disabilities or learning disabilities.

Parental fatigue was found to have a significant correlation with the difficulty in reconciling support for children in distance learning and working activities, without the possibility of using domestic help perhaps previously used. One of the most alarming results of the study conducted was the high percentage of women who said they would consider leaving work in the event of an extension of distance learning.

A second incident variable was the presence of special educational needs. A high percentage of these families, unfortunately, did not receive any support during the months of lockdown. This was a real abandonment of families with a greater burden of fatigue.

These aspects of disorientation, fatigue, and parental stress regarding forms of homeschooling confirm both studies prior to the 2020 pandemic event (Boulton, 2008; Liu et al., 2010; Murphy, Rodriguez-Manzanares, 2009; Selwyn et al., 2011) and national and international studies conducted during the period of interest for our study (Ardizzoni et al., 2020; Garbe et al., 2020; Mantovani et al., 2020).

On the one hand, we can hypothesize that we intercepted a sample of mothers with great motivation to guarantee their children a high level of education and that they were strongly motivated to carefully follow the scholastic success of their children, and therefore, for this reason, we collected the opinions of women who were more exposed to the risk of stress regarding this aspect of child-rearing.

On the other hand, it is realistic to consider that the negative impact of the absence of in-person school pointed out by these families may have been even more profound and structural in families living in conditions of socio-economic hardship, with fewer material-instrumental resources and, in general, with less cultural capital. We did not intercept these families in this study, but other studies have focused on them. It has been documented how distance learning can exacerbate existing socio-economic inequalities and long-running vulnerabilities for fragile or marginalized families, struggling with limited or non-existent access to technological resources or the internet at home, and that provide less parental guidance (Burgess, Sievertsen, 2020; Cardenas, Bustos, Chakraborty, 2020; Masonbrink, Hurley, 2020; Murat, Bonacini, 2020; STC, 2020a; Van Lancker, Parolin, 2020; Yip, 2020).

With regard to children and adolescents, the perspective offered by the mothers in the sample was mainly of concern, both with respect to their relationship with distance learning and their lack of autonomous 
skills to cope with this new task, and with respect to an overall emotional and behavioral stressful condition, which we cannot consider referable only to distance learning, but rather to the cumulative impact of several factors (Morelli et al., 2020; Petretto, Masala, Masala, 2020; Segre et al. 2020; Spinelli et al., 2020). The positive impact of having access to openair spaces on children's and parents' well-being, which emerged in our study, confirmed this cumulative and multifactorial reading.

Despite the recognition by mothers of positive aspects regarding the increase of digital skills in their children (as in Vuorikari et al., 2020) and the greater transparency of the teaching activities of teachers, the prevalent perception of distance learning was clearly negative. Parents observed in their children signs of demotivation, emotional fatigue in remote communication and assiduous requests for support, particularly by primary school children, but surprisingly by secondary school students as well.

The participants in our study also valued distance learning as a way to restore the relationship between children and teachers (as in Ciurnelli, Izzo, 2020). The support to the socio-emotional condition of children and families and the maintenance of 'connections' was indicated as one of the main aims of remote teaching in the National Guidelines on remote educational connections in the ECEC services (MIUR, 2020), a perspective that can be extended to the whole school system. But, at the same time, mothers observed a great nostalgia in their children for their classmates as well as teachers, and their social life that characterized the in-person school.

It seems to us, therefore, that the demotivation of children and young people towards distance learning can be partly explained by the difficulties of teachers (understandable given the sudden demand) and of the students themselves in adapting to distance learning, starting from a didactic experience barely integrated on a digital level. In addition, the mainly transmissive, synchronous or asynchronous, characteristics of the didactic proposals were not very engaging. However, this demotivation must be read in the light of the overall emotional and behavioral picture that emerged (due to boredom, poor concentration, a sense of frustration, mood swings, restlessness, melancholy, anger, and loneliness), emotions and behaviors also caused by the lockdown restrictions, the total absence of in-person school activities and other extracurricular activities. The total closure of social and activity spaces constituted a real counter-evolution in the growth path of children and adolescents.

These results warn us against considering the question of distance learning as purely methodological, in terms of teaching techniques and the variety of tools, and as purely related to learning. It is obviously de- 
sirable that teachers should receive adequate professional development in the use of ICTs in order to be able to offer active and engaging teaching, also with the use of technologies. However, in a systemic perspective, distance teaching, especially if taken as the only form of teaching, weakens the in-person social experience of learning and school life in a structural way. Even if offered with the best possible methodological approach, it overloads the parental figures, generating stress linked both to the task of supporting children in attending distance learning and to reconciling the commitments and activities, primarily related to work, which distinguish adult and family life.

Therefore, distance school is no longer "school" as we are used to understanding it. It is something else, lacking the role - that constitutively distinguishes "in-person school" - of socio-cultural protection, parental support, and social arena.

\section{References}

Angrist J.D., Battistin E., Vuri D. (2017): In a Small Moment: Class Size and Moral Hazard in the Italian Mezzogiorno. American Economic Journal: Applied Economics, 9(4), pp. 216-249.

Ardizzoni S., Bolognesi I., Salinaro M., Scarpini M. (2020): Didattica a distanza con le famiglie: l'esperienza di insegnanti e genitori, in Italia e in Cina, durante l'emergenza sanitaria 2020. Uno studio preliminare. In A. Gigli: Infanzia, famiglie, servizi educativi e scolastici nel Covid-19. Bologna: CREIF, pp. $71-79$ (https://centri.unibo.it/creif/it/pubblicazioni/servizi-educativi-escolastici-nel-covid-19-riflessioni-pedagogiche; last access: 29.12.20).

Azevedo J.P., Hasan A., Goldemberg D., Iqbal S.A., Geven K. (2020): Simulating the Potential Impacts of COVID-19 School Closures on Schooling and Learning Outcomes: A Set of Global Estimates. Policy Research Working Paper, No. 9284. Washington: World Bank.

Baker R.P. (1998): Computer Assisted Survey Information Collection. New York: John Wiley \& Son.

Berlyne D.E., Peckham S. (1966): The Semantic Differential and other Measures of Reaction to Visual Complexity. Canadian Journal of Experimental Psychology, 20(2), pp. 125-135.

Bhamani S., Makhdoom A.Z., Bharuchi V., Ali N., Kaleem S., Ahmed D. (2020): Home Learning in Times of COVID: Experiences of Parents. Journal of Education and Educational Development, 7(1), pp. 9-26.

Boals A., Hathaway L.M. (2010): The Importance of the DSM-IV E and F Criteria in Self-Report Assessments of PTSD. Journal of Anxiety Disorders, 24(1), pp. 161-166. 
Bollen K.A., Pearl J. (2013): Eight Myths about Causality and Structural Equation Models. In S.L. Morgan (Ed.): Handbook of Causal Analysis for Social Research. Dordrecht (NL): Springer, pp. 301-328.

Boonk, L., Gijselaers H.J., Ritzen H., Brand-Gruwel S. (2018): A Review of the Relationship between Parental Involvement Indicators and Academic Achievement. Educational Research Review, n. 24, pp. 10-30.

Boulton H. (2008): Managing e-Learning: What Are the Real Implications for Schools? The Electronic Journal of e-Learning, 6(1), pp. 11-18.

Brooks S.K., Webster R.K., Smith L.E., Simon Wessely S., Greenberg N., Rubin G.J. (2020): The Psychological Impact of Quarantine and How to Reduce it: Rapid Review of the Evidence. The Lancet, 395(10227), pp. 912-920.

Brown S.M., Doom J.R., Lechuga-Peña S., Watamura S.E., Koppels T. (2020): Stress and Parenting during the Global COVID-19 Pandemic. Child Abuse E Neglect, 110(104699), nn.p.n.i.

Burgess S., Sievertsen H. H. (2020): Schools, Skills, and Learning: The Impact of COVID-19 on Education (https://voxeu.org/article/impact-covid-19-education; last access: 29.12.20).

Brazzelli E., Grazzani I., Pepe A. (2021): Promoting Prosocial Behavior in Toddlerhood: A Conversation-Based Intervention at Nursery. Journal of Experimental Child Psychology, 204(105056).

Bulkley K., Fisler J. (2003): A Decade of Charter Schools: From Theory to Practice. Educational Policy, 17(3), pp. 317-342.

Brunello G., Checchi D. (2005): School Quality and Family Background in Italy. Economics of Education Review, 24(5), pp. 563-577.

Cardenas M.C., Bustos S.S., Chakraborty R. (2020): A "Parallel Pandemic": The Psychosocial Burden of COVID-19 in Children and Adolescents. Acta Paediatrica, 109(11), pp. 2187-2188.

Centifanti L.C., Williams D.M. (Eds.) (2017): The Wiley Handbook of Developmental Psychopathology. New York: John Wiley \& Son.

Champeaux H., Mangiavacchi L., Marchetta F., Piccoli L. (2020): Learning from Home: Children's Cognitive and Socio-Emotional Skills during the Covid-19 Lockdown in France and Italy. Institute of Labor Economics (IZA) Discussion Papers 13819 (https://www.aiel.it/cms/cms-files/submission/ all20200904120231.pdf; last access: 29.12.20).

Ciurnelli B., Izzo D. (2020): L'impatto della pandemia sulla didattica: percezioni, azioni e reazioni dal mondo della scuola. Lifelong Lifewide Learning, 16(36), pp. 26-43.

Epstein J.L. (2018): School, Family, and Community Partnerships: Preparing Educators and Improving Schools. New York: Routledge.

Fontanesi L., Marchetti D., Mazza C., Di Giandomenico S., Roma P., Verrocchio M. C. (2020): The Effect of the COVID-19 Lockdown on Parents: A Call to Adopt Urgent Measures. Psychological Trauma: Theory, Research, Practice, and Policy, 12(S1), pp. S79-S81. 
Garbe A., Ogurlu U., Logan N., Cook P. (2020): Parents' Experiences with Remote Education during COVID-19 School Closures. American Journal of Qualitative Research, 4(3), pp. 45-65.

Gigli A. (2020): Essere genitori ai tempi del COVID19: disagi, bisogni, risorse: i primi dati di una rilevazione. RIEF-Rivista Italiana di Educazione Familiare (just accepted paper).

Green C.L., Hoover-Dempsey K.V. (2007): Why do Parents Homeschool? A Systematic Examination of Parental Involvement. Education and Urban Society, 39(2), pp. 264-285.

Günther-Bel C., Vilaregut A., Carratala E., Torras-Garat S., Pérez-Testor C. (2020): A Mixed-Method Study of Individual, Couple, and Parental Functioning during the State-Regulated COVID-19 Lockdown in Spain. Family Process, 59(3), pp. 1060-1079.

Hoffman J.A., Miller E.A. (2020): Addressing the Consequences of School Closure due to COVID-19 on Children's Physical and Mental Well-Being. World Medical E Health Policy, 12(3), pp. 300-310.

ISTAT (2018): Popolazione e famiglie. Annuario Statistico Italiano 2018 (https:// www.istat.it/it/files//2018/12/C03.pdf; last access: 29.12.20).

ISTAT (2019): Livelli di istruzione e ritorni occupazionali (https://www.istat. it/it/files/2020/07/Livelli-di-istruzione-e-ritorni-occupazionali.pdf; last access: 29.12 .20$)$.

ISTAT (2020): Spazi in casa e disponibilità di computer per bambini e ragazzi. Retrieved from: https://www.istat.it/it/files//2020/04/Spazi-casa-disponibilita-computer-ragazzi.pdf; last access: 29.12.20).

Jones A.L., Kessler M.A. (2020): Teachers' Emotion and Identity Work during a Pandemic. Frontiers in Education, n. 5, p. 195.

Kim L.E., Asbury K. (2020): "Like a Rug Had Been Pulled from Under You": The Impact of COVID-19 on Teachers in England during the First Six Weeks of the UK Lockdown. British Journal of Educational Psychology, 90(4), pp. 1062-1083.

Kuhfeld M., Tarasawa B. (2020): The COVID-19 Slide: What Summer Learning Loss Can Tell Us about the Potential Impact of School Closures on Student Academic Achievement. NWEA White Paper (https://www.nwea.org/content/uploads/2020/05/Collaborative-Brief_Covid19-Slide-APR20.pdf; last access: 29.12.20).

Lancker W., van, Parolin Z. (2020): COVID-19, School Closures, and Child Poverty: a Social Crisis in the Making. Lancet Public Health, n. 5, e243-e244. Liu F., Black E., Algina J., Cavanaugh C., Dawson K. (2010): The Validation of One Parental Involvement Measurement in Virtual Schooling. Journal of Interactive Online Learning, 9(2), pp. 105-132.

Mangiavacchi L., Piccoli L., Pieroni L. (2020): Fathers Matter: Intra-Household Responsibilities and Children's Wellbeing during the COVID-19 Lockdown in Italy. Institute of Labor Economics (IZA) Discussion Papers 13519 (http:// ftp.iza.org/dp13519.pdf; last access: 29.12.20). 
Mantovani S., Picca M., Ferri P., Bove C., Manzoni P. (2020): Bambini e lockdown. La parola ai genitori (https://www.unimib.it/sites/default/files/ Report_Bambini_e_lockdown.pdf; last access: 29.12.20).

Masonbrink A.R., Hurley E. (2020): Advocating for Children during the COVID-19 School Closures. Pediatrics, 146(3).

MIUR (2020): Orientamenti pedagogici sui Legami educativi a Distanza, https:// www.miur.gov.it/documents/20182/2432359/ORIENTAMENTI+PEDAG OGICI+SUI+LEAD.pdf/cdf36ed7-0ce7-70fa-6ab2-6983fe2f035c?version $=1.1 \& \mathrm{t}=1589889085827$ (last access: 29.12.20).

Morelli M., Cattelino E., Baiocco R., Trumello C., Babore A., Candelori C., Chirumbolo A. (2020): Parents and Children During the COVID-19 Lockdown: The Influence of Parenting Distress and Parenting Self-Efficacy on Children's Emotional Well-Being. Frontiers in Psychology, n. 11, p. 2584.

Murat M., Bonacini L. (2020): Coronavirus Pandemic, Remote Learning and Education Inequalities. Global Labor Organization (GLO) Discussion Paper 679 (https://ideas.repec.org/p/zbw/glodps/679.html; last access: 29.12.20).

Murphy E., Rodriguez-Manzanares M.A. (2009): Teachers' Perspectives on Motivation in High School Distance Education. Journal of Distance Education, 23(3), pp. 1-24.

Nader K. (2007): Understanding and Assessing Trauma in Children and Adolescents: Measures, Methods, and Youth in Context. New York: Routledge.

Noble K., Hurley P., Macklin S. (2020): COVID-19, Employment Stress and Student Vulnerability in Australia. Mitchell Institute for Education and Health Policy, Victoria University (https://www.vu.edu.au/sites/default/files/ COVID-19\%20employment \%20stress\%20and\%20child\%20vulnerability.pdf; last access: 29.12.20).

Osgood C.E. (1964): Semantic Differential Technique in the Comparative Study of Cultures. American Anthropologist, 66(3), pp. 171-200.

Ornaghi V., Pepe A., Agliati A., Grazzani I. (2019): The Contribution of Emotion Knowledge, Language Ability, and Maternal Emotion Socialization Style to Explaining Toddlers' Emotion Regulation. Social Development, 28(3), pp. 581-598.

Pallavicini, F., Pepe, A. (2020). Virtual Reality Games and the Role of Body Involvement in Enhancing Positive Emotions and Decreasing Anxiety: Within-Subjects Pilot Study. JMIR Serious Games, 8(2), e15635.

Pagani V., Falcone C., Pastori G., Zaninelli F.L. (2020): Povertà educativa, diritto all'educazione e approccio alle capacità. La voce di educatrici e insegnanti dei servizi educativi per l'infanzia e di scuola primaria. Scholé, n. 2, pp. 181-188.

Pagani V., Passalacqua, F. (2020). "Da un giorno all'altro abbiamo dovuto cambiare lavoro". L'esperienza della scuola a distanza dalla voce degli insegnanti. RicercAzione, 12(2), pp. 101-116.

Park S., Holloway S.D. (2017): The Effects of School-Based Parental Involvement on Academic Achievement at the Child and Elementary School Level: A Longitudinal Study. The Journal of Educational Research, 110(1), pp. 1-16. 
Pearl J. (2012). The Mediation Formula: A Guide to the Assessment of Causal Pathways in Nonlinear Models. In C. Berzuini, P. Dawid, L. Bernardinelli (Eds.): Causality: Statistical Perspectives and Applications. Chichester (UK): John Wiley \& Sons, pp. 151-179.

Petretto D.R., Masala I., Masala C. (2020): School Closure and Children in the Outbreak of COVID-19. Clinical Practice and Epidemiology in Mental Health, n. 16, pp. 189-191.

Podsakoff P.M., MacKenzie S.B., Lee J.Y., Podsakoff N.P. (2003): Common Method Biases in Behavioral Research: A Critical Review of the Literature and Recommended Remedies. Journal of applied psychology, 88(5), p. 879.

Poletti M., Raballo A. (2020): Letter to the Editor: Evidence on School Closure and Children's Social Contact: Useful for Coronavirus Disease (COVID-19)? Euro Surveill, 25(17), e2000758.

Save the Children (2020a): Riscriviamo il futuro. L'impatto del coronavirus sulla povertà educativa. Roma: Save the Children (https://s3.savethechildren.it/ public/files/uploads/pubblicazioni/limpatto-del-coronavirus-sullapovertaeducativa_0.pdf; last access: 29.12.20).

Save the Children (2020b): La scuola che verrà: attese, incertezze e sogni all'avvio del nuovo anno scolastico. Roma: Save the Children (; https:// s3.savethechildren.it/public/files/uploads/pubblicazioni/la-scuola-che-verra.pdflast access: 29.12.20).

Segre G., Campi R., Scarpellini F., Clavenna A., Zanetti M., Cartabia M., Bonati M. (2020): Interviewing Children: The Impact of the COVID-19 Quarantine on Children's Changes in Routine and Psychological Distress. Research Square (pre-print).

Selwyn N., Banaji S., Hadjithoma-Garstka C., Clark W. (2011): Providing a Platform for Parents? Exploring the Nature of Parental Engagement with School Learning Platforms. Journal of Computer Assisted Learning, 27(4), pp. 314-323.

Società Italiana di Ricerca Didattica - SIRD (2020): Per un confronto sulle modalità di didattica a distanza adottate nelle scuole italiane nel periodo di emergenza COVID-19 (https://www.sird.it/wpcontent/uploads/2020/07/ Una_prima_panoramica_dei_dati.pdflast access: 29.12.20).

Soriani, A. (2020): Nessuno (digitalmente) indietro? Le sfide di una scuola forzata alla non-presenza. In: Gigli A., Infanzia, famiglie, servizi educativi e scolastici nel Covid-19. Bologna: CREIF, pp. 31-34 (https://centri.unibo.it/ creif/it/pubblicazioni/servizi-educativi-e-scolastici-nel-covid-19-riflessionipedagogiche; last access: 29.12.20).

Spinelli M., Lionetti F., Pastore M., Fasolo M. (2020): Parents' Stress and Children's Psychological Problems in Families Facing the COVID-19 Outbreak in Italy. Frontiers in Psychology, n. 11, pp. 1-7.

Tan C.Y., Lyu M., Peng B. (2020): Academic Benefits from Parental Involvement Are Stratified by Parental Socioeconomic Status: A Meta-Analysis. Parenting, 20(4), pp. 241-287. 
UNESCO (2020): COVID-19 Educational Disruption and Response (https:// en.unesco.org/covid19/educationresponse; last access: 29.12.20).

United Nations (2020): The impact of Covid-19 on children the. Policy Brief (https://unsdg.un.org/resources/policy-brief-impact-covid-19-children; last access: 22.2.21).

Veronese G., Pepe A. (2017): Positive and Negative Affect in Children Living in Refugee Camps: Assessing the Psychometric Proprieties and Factorial Invariance of the PANAS-C in the Gaza Strip. Evaluation \& the Health Professions, 40(1), pp. 3-32.

Veronese G., Pepe A., Almurnak F., Jaradah A., Hamdouna H. (2018): Quality of Life, Primary Traumatisation, and Positive and Negative Effects in Primary School Students in the Gaza Strip. The Lancet, 391, p. S14.

Veronese G., Pepe A., Alzaanin W., Shoman H. (2020): Sources of Functioning, Symptoms of Trauma, and Psychological Distress: A Cross-Sectional Study with Palestinian Health Workers Operating in West Bank and Gaza Strip. American Journal of Orthopsychiatry, 90(6), pp. 751-759.

Viner R.M., Russell S.J., Croker H., Packer J., Ward J., Stansfield C., Mytton O., Bonell C., Booy R. (2020): School Closure and Management Practices during Coronavirus Outbreaks Including COVID-19: A Rapid Systematic Review. The Lancet, 4(5), pp. 397-404.

Vuorikari R., Velicu A., Chaudron S., Cachia R., Di Gioia R. (2020): How Families Handled Emergency Remote Schooling during the Covid-19 Lockdown in Spring 2020 - Summary of Key Findings from Families with Children in 11 European Countries. Luxembourg: Publications Office of the European Union (https://publications.jrc.ec.europa.eu/repository/bitstream/ JRC122303/remote_schooling_families_summary.pdf; last access:29.12.20).

Yip T. (Ed.) (2020): Addressing Inequities in Education during the COVID-19 Pandemic: How Education Policy and Schools Can Support Historically and Currently Marginalized Children and Youth. Washington: SRCD (https:// www.srcd.org/sites/default/files/resources/FINAL_AddressingInequalitiesVolume-092020.pdf; last access: 29.12.20).

Wyatt R.C., Meyers L.S. (1987): Psychometric Properties of Four 5-Point Likert Type Response Scales. Educational and Psychological Measurement, 47(1), pp. 27-35. 